\title{
Violence in mental disorders and community sample: An evolutionary model related with dominance in social relationships
}

\author{
F. Montañés-Rada ${ }^{a, b, *}$, J.M. Ramírez ${ }^{\text {a,c }}$, M.T. De Lucas Taracena ${ }^{d}$ \\ a Department of Psychobiology, Complutense University, Madrid, Spain \\ ${ }^{\mathrm{b}}$ Chief of Psychitary Department, Alcorcón Hospital, Madrid, Spain \\ c Institute for Biofunctional Studies, Psychobiology Department, Complutense University, Madrid, Spain \\ d Usera Health Center, Madrid, Spain
}

Received 26 October 2005; accepted 22 February 2006

Summary The major risk determinants of violence are to be young and male, to have low socioeconomic status and suffering substance abuse. This is true whether it occurs in the context of a concurrent mental illness or not; i.e., mental disorders are neither necessary, nor sufficient causes for violence.

Intense motivation is a facilitating factor for violence in clinical and non clinical samples. This explains why 'normal' people, are implicated in planned violence at higher rates than mentally ill (e.g. in criminal acts against property). However mentally ill patients are more easily implicated in impulsive violence or in violence without obvious cause due to veiled motivation fuelled by unidentified symptoms. Subjective or real awareness of competitive disadvantage increases motivation for violence (e.g. paranoid, narcissistic symptoms, etc.). Many psychiatric disorders as antisocial disorder, borderline, schizophrenia, have most of the factors that facilitate the appearance of violence. Antisocial disorder is a good model to study determinants of violence in normal samples as it is present in young males that do not have any psychotic symptom, have stable symptomatology, self control under scrutiny, and their motivations are similar to normal samples.

Our evolutionary model suggests that there is a non random association of genetic factors (genes, pseudogenes, promoting areas, etc.), that is, a genetic cluster (cluster DO), whose phylogenetic function is to motivate to be the dominant in social relationships.

To be the dominant is a major psychological feature present in many social groups of animals, included primates. DO cluster have sense from an evolutionary viewpoint: when expressed in no pathological way it increases inclusive fitness (transmission of the genes of a person genotype whether by oneself or by relatives reproduction).

Features of cluster DO in humans are expressed differently according to sex, age, moral education, level of intelligence, etc. Cluster DO has higher phenotypical expression in males and young people.

Primary antisocial personality disorder and other related disorders (cluster B personality disorders, disocial, defiant disorder, etc.), are a pathological manifestation of this cluster DO. Some other genetic clusters that causes the genetic

\footnotetext{
Corresponding author. Present address: Fundación Hospital Alcorcón, C/Budapest 128922 Alcorcón, Madrid, Spain. Tel.: +34 91 6219851; fax: +34916219219.

E-mail address: fmontanes@fhalcorcon.es (F. Montañés-Rada).
} 
liability to some disorders (e.g. attention deficit disorder) are non random associated with cluster DO, thus explaining clinical comorbidity.

According to our model, motivation for dominance usually prevails over motivation for material benefit or antinormative behaviour, this explains some incongruent behaviour in antisocial patients not elucidated by other models.

Along with the primary expressed feature of dominance of cluster DO there are other secondary features that have been identified by psychobiological studies: novelty seeking, intolerance for frustration, impulsiveness, fearless, aggressiveness, higher threshold for activation of the sympathetic system, lack of empathy, egoism, non acceptance of rules, defiant and rebellious behaviour, manipulation in social interactions, selfishness and deficits in altruism or in social co-operation.

\section{Introduction}

We will propose an evolutionary model to explain epidemiological data on violence after analysing data on mental disorders and particularly on antisocial personality disorder (APD). Therefore there are three parts in this article:

1. An update on violence and mental illness.

2. A summary on relationships between violence, hierarchical dominance, social cooperation and APD.

3. A proposal of a new evolutionary model to explain violence, aggressiveness and lack of social cooperation related with dominance in social relationships. This model also explains APD as a developmental pathological manifestation.

\section{Violence and mental illness}

Unless otherwise stated, 'violence' will refer to acts of physical violence against others. The term 'mental illness' will be reserved for non-substancerelated disorders, usually major mental ilnesses such as schizophrenia or depression. Substance-related disorders and concurrent substance abuse will be identified and discussed as separate risk factors.

Following an excellent review on relationship between violence and mental illness [1], we will try to answer three questions: Are the mentally ill violent? Is there an increased risk of violence by the mentally ill? Is the population at risk?

\section{Are the mentally ill violent?}

Mental illness and violence appear associated in public media. Many psychiatrists report direct experiences with violent behaviour among the mentally ill. For instance, in Canada 50\% of their psychiatrists report having been assaulted by a patient at least once [2]. Rates of aggressive behaviours however differ dramatically, even in treatment units with a similar clinical mix and severity, indicating that there are other factors besides the presence of mental illness [3]. Most incidents have important social/structural antecedents, such as ward atmosphere and restrictions, lack of clinical leadership, overcrowding, lack of activities, or poorly structured activity transitions $[4,5]$.

The public judge the risk of violence differently, depending on the diagnostic group. For example, in an American survey $(N=1444)$, while the probability of violence was universally overestimated for mentally ill compared with normal population, respondents correctly ranked substance abusers among the highest risk groups [6]. People fear mostly random, senseless, and unpredictable violence, associating it with mental illness [7].

A history of victimization and bullying may predispose the mentally ill to react violently when provoked [8].

\section{Is there an increased risk of violence by the mentally ill?}

Definite statements are difficult to make. It is equally possible to find in recent literature support for the conclusions that the mentally ill are no more violent, as that they are as violent, or that they are even more violent than their non-mentally ill counterparts [9].

Until a quarter of century ago, the prevailing point of view was that mentally ill were no more likely to be violent that not mentally ill people, and often even less. More recent studies have reported a modest association between mental illness and violence, even when these elements have been controlled $[6,8-10]$. The nature of this association, however, remains unclear given the significant methodological challenges faced by researchers in this field, as it has been pointed out by the recent MacArthur Violence Risk Assessment Study completed in the United States $[11,12]$. This study has made a intensive effort to address methodological 
problems, finding that the prevalence of violence among those with a major mental disorder who did not abuse substances, was indistinguishable from their non-substance abusing neighbourhood controls. Concurrent substance abuse disorder doubled the risk of violence. Those with schizophrenia had the lowest occurrence of violence over the course of the year (14.8\%), compared to those with a bipolar disorder $(22.0 \%)$ or with major depression (28.5\%).

\section{Is the population at risk?}

Violent incidents among persons with serious mental disorders are related with their social conditions, and the nature and quality of their closest social interactions [13]. The most likely targets of violence were family members or friends $(87 \%)$, and the violence typically occurred at home $[10,14]$.

To what extent do mentally ill patients contribute to the overall prevalence of community violence? The Epidemiologic Catchment Area studies conducted in the United States [15] reported an attributable risk of $4.3 \%$ for those with a major mental disorder, whereas the population attributable risk was $3.4 \%$ for those with a substance abuse disorder, and $5 \%$ for those with a co-morbid mental illness and substance abuse disorder. Therefore, by these estimates, violence in the community could be reduced by less than $5 \%$ if major mental disorders could be eliminated, and by only $10 \%$ if both, major mental disorders and co-morbid disorders, were eliminated. However it might be reduced by over a third if substance abuse disorders were eliminated.

\section{Discussion and summary}

This overview on violence in mental disorders supports some conclusions. Mental disorders are neither necessary, nor sufficient causes of violence. The major determinants of violence are to be young and male, and a low socioeconomic status. Substance abuse also appears to be a major determinant of violence, whether it occurs in the context of a concurrent mental illness or not. In our experience drug consumption motivates to violence action in several ways. First, there is an urge to obtain money and this leads to a planned criminal action. Second, withdrawal and intoxication periods increase the risk of impulsive and unexpected violence. Third, there are personality features that predispose both to drug consumption and impulsive behaviour.
Facilitating and releasing factors are also important. This is obvious when analysing reactions to similar motivational situations in different people. Some situations that promote intense motivation to violence differ across cultures, whereas others are similar in all cultures, such as being humiliated, or being robbed. This explains why some situations trigger a violent act more easily in some specific cultures, and others seem to be universal [16].

In our opinion motivation is one of the most important factor for violence. If intense motivation is reached, everybody may carry out a violent action. For example, a characteristic of obsessive personality is the respect of norms and law. However, if motivation to carry out their obsessive thoughts reaches its peak, aggressive behaviour may appear. The need to reach intense motivation explains why 'normal' people, are implicated in planned violence at higher rates than mentally ill (for example, in criminal acts against property). However mentally ill patients are more easily implicated in impulsive violence or in violence without obvious cause. This is due to the presence of delusions, hallucinations, drug or alcohol consumption. In fact there is an unexplained discordance between delusions and hallucinations content and conduct of patients. Drug consumption release inhibitions and facilitate patients to be violent and to have a conduct concordant with the content of delusions or hallucinations (e.g. to kill some relative who is the devil, etc.). This unpredictability is what frightens and what is responsible of public perception of mentally ill as more aggressive.

Something that increase the motivation to being aggressive or at least to cheat is the subjective or real awareness of competitive disadvantage in: age, health, physical attractiveness, socioeconomic status, intelligence, etc. $[17,18]$. Situations is which competition increases have a roll as well, such us: urban settings and some cultures [19].

In summary, mentally ill patients not only have symptoms that increase motivation to violence but also many of the factors that facilitate the onset of violence. Some disorders, such as schizophrenia, or antisocial personality, have a greater risk of aggregating all these factors. From a biological point of view, being either young or male are the most important risk factors in committing violence. As already stated, they are neither sufficient, nor necessary causes for violence. This is why the study of a disorder in which males are predominant and in which violence appears from childhood and decreases in adult ages may be of help in elucidating these factors. Among all disorders described in DSM IV associated with crime 
and violence there is one of them with a sex ratio of three to four males by one woman and with a decrease in severity at 30 year old. This condition is APD [20]. Criminal population and APD overlap, therefore a subset of them share the same label $[21,22]$.

\section{APD, sociopathy, psycopathy, and violence}

\section{APD}

APD, as coded in DSM-IV TR [20], is the paradigm of aggressiveness, in fact violence and law breakdowns are part of the diagnostic criteria. It is characterized as being a pervasive disregard for, and violation of, rights of others since the age of 15 . A person must be at least 18 years old and have displayed evidence of conduct disorder before the age of 15 . Prevalence rates for APD are of $3 \%$ for males and $1 \%$ for females in the general population. This disorder may be underestimated in females, given the emphasis on aggressive items in DSM-IV. A high frequency of APD is also associated with low socioeconomic status and urban settings.

Antisocial, narcissistic, and histrionic personality disorders are spectrum disorders, meaning this that they are different expressions of the same liability. The three disorders have been shown to aggregate in the same family and coexist in the same person. Therefore, although phenotypically distinguishable, they may reflect different expressions of a common liability. Symptoms of the three disorders tend to group around impulsiveness, aggression, and dramatic affects [20], and may be complicated by dysphoria, tension, low tolerance for boredom, depressed mood, and premature violent death. Impairment is extremely variable, but typically includes social difficulties [20].

APD is more frequent among the first-degree biological relatives of probands with this disorder. Biological relatives of women with APD are at greater risk for the same disorder than that of men. Genetic studies have suggested family transmission of APD, substance abuse, and somatization disorder, with the former two being characteristic of males and the latter of females in the same family. Adoption studies show that both: genetic and environmental factors contribute to the risk for this disorder, since both: adopted and biological children of parents with APD are at increased risk of suffering this disorder [20].

Conduct disorder (before the age of 10) and concomitant attention-deficit/hyperactivity disor- der increases the likelihood of developing APD in adult life. Conduct disorder is more likely to develop into APD when there is erratic parenting, neglect, or inconsistent parental discipline. APD decreases in severity with age higher than $30-40$ years old [20].

\section{Problems with classifications}

Current psychiatric classification (DSM IV) has diagnostic criteria of APD based on observations of violation of society rules that are considered illegal (criminal) actions. Those criteria give a high inter-rater reliability, but have two problems. First of all is that antisocial diagnose is an exception in modern psychiatric classifications based upon questioning patients about the motivations of their actions. Secondly, there is an excessive emphasis on illegal actions. Thus, these criteria may exclude many cases of APD not expressed through illegal actions but, for example, with the manipulation of others, which is more characteristic of narcissistic or histrionic disorders. These problems explain why, for many psychiatrists, the antisocial patient is only the hard core of a broader spectrum. Another problem associated with the phenotypical expression of the disorder is related with gender and cultural level. Females may not express the predisposition as APD but as a somatoform or histrionic disorder. Furthermore, in our opinion higher cultural levels may help an antisocial predisposition to express itself without criminal actions or direct aggression.

Those, and similar problems, have a reflection in the profuse terminology related with the disorder in non-psychiatric settings: sociopathy, moral insanity, psychopathy, etc., which usually broadens the concept defined by DSM IV, incorporating symptoms of other disorders such as narcissistic or histrionic personality disorders.

Some authors make a typological distinction between psychopaths and sociopaths [24]. The term psychopath is used to refer to antisocial individuals who are of relatively high intelligence and middle to upper socioeconomic status and who express their aberrant behaviour in impressive and sometimes socially skilled behaviour which may or may not be criminal, such as insider trading on the stock market [25]. On the contrary, these authors reserve the term sociopath for those antisocial persons who have relatively low intelligence and social skills or who come from the lower socioeconomic stratum and express their antisocial nature in the repeated commission of violent crime or crimes to property. 
Other authors make a distinction between simple and hostile [26], or primary and secondary psychopaths or sociopaths [27], reserving the term simple or primary for those individuals characterised by a complete lack of social emotions. Individuals who exhibit antisocial behaviour in the absence of this emotional deficit are called hostile or secondary psychopaths or sociopaths, or even pseudopsychopaths [28].

\section{Violence and APD}

According to USA records, sociopaths comprise only $3-4 \%$ of the male population and less than $1 \%$ of the female population [29-31]. However, they are thought to account for approximately $20 \%$ of the prison population [32] and between 33\% and $80 \%$ of the population of chronic criminal offenders [33-35]. Whereas the "typical" American burglar is estimated to have committed an average of five crimes per year before being apprehended, chronic offenders (those most likely to be sociopaths) report committing upward of 50 crimes per year and sometimes as many as 200 or 300 [36]. Collectively, these individuals are thought to account for over $50 \%$ of all crimes in the US $[32,37,38]$.

\section{Conclusion}

APD is more prevalent in males, it is characterized by violence and aggressiveness with disregard to social norms, has a higher severity in its expression in young people and a decreasing severity with age. In general population major determinants of violence are to be male and young and some socioeconomic factors. Therefore, APD is a good model and its study may highlight this epidemiological data in general population. We think that the association of all these characteristics in APD is a phenotypical expression of a genetic vulnerability that requires an evolutionary explanation.

\section{An evolutionary approach to the APD}

\section{Linda Mealey's approach}

Linda Mealey [24] characterized sociopaths by the successful execution of social deception, being the product of evolutionary pressures which, through a complex interaction of environmental and genetic factors, lead some individuals to pursue a life strategy of manipulative and predatory social interactions. On the basis of game theoretic models this strategy is to be expected in the population at relatively low frequencies (in a demographic pattern consistent with what we see in contemporary societies). According to her: [1] there is a genetic predisposition underlying sociopathy which is normally distributed in the population [2]. A small, fixed percentage of individuals - those at the extreme of this continuum - will be deemed 'morally insane' in any culture, as the result of selection to fill a small, frequency-dependent, evolutionary niche [3]. A variable percentage of individuals who are less extreme on the continuum will sometimes pursue a life-history strategy that is similar to that of their 'morally insane' colleagues, in response to environmental conditions during their early development [4]. A subclinical manifestation of this underlying genetic continuum is evident in many of us, becoming apparent only when immediate environmental circumstances make an antisocial strategy more profitable than a prosocial one. This author carries out an excellent review on personality, temperament, game theory, emotions, etc., to support her model that is focused in the integration of all these data in the defence of the existence of primary and secondary sociopaths.

\section{Our proposed model}

We agree with most of Mealey's assessments and the logic underlying her model, but we differ in the nature of the genetic predisposition.

In our opinion, the presence of antisocial behaviour (rule breakdown, aggressiveness, etc.) in normal population, specially in the male and young, along with changes in phenotypical expression according to sex or environmental circumstances (somatization disorder, narcisism, histrionism, drug use, etc.), suggests that APD is an extreme manifestation of some psychological features expressed by genetic factors (polimorfism, activation of promoting areas, genes, pseudogenes, variants, etc.) that are present in normal population. These genetic factors should have an evolutionary (phylogenetic) function as have not been counter-selected, expressing themselves as adaptative functions in normal population.

For us, social deception, as proposed by Mealey, may be only a phenotypic expression of the real liability to develop an APD. Another phenotypic expression used by APD to get their objectives is aggressiveness. APD diagnosis is associated with the presence or use of many other psychological or physical strategies that we call temperament features, vulnerability to stress, etc., which we analyse further in detail. All these strategies have a phylogenetic function that help APD in the pros- 
ecution of the objective to which they are motivated to look for. This motivation of APD behaviour is the core liability to develop an APD.

From an evolutionary perspective, primary APD may be an extreme phenotypical expression of a particular cluster of genetic factors (we will call it cluster DO). The concept of genetic factor includes; polimorfism, activation of promoting areas, genes, pseudogenes, variants, etc. The core genetic factors of cluster DO express phenotypically a predisposition to establish dominance in social relationships. Secondary APD may be due to another cluster of genetic factors (B, $C$, etc.) or by a lower degree of expression (in severity) of the features of this cluster DO. Of course phenotypical expression means that genetic factors interact with environment. Around the core feature expressed by some genetic factors of this cluster DO (dominance) there are other psychological features (e.g. selfishness, novelty seeking, etc.) which are coded by other genetic factors of the very same cluster. However these later genetic factors have a genetic expression that is less intense (either due to gene interaction or by a higher vulnerability to environmental influences).

Cluster DO is the product of a non-random association in the genetic transmission of genetic factors. This non-random association has sense from an evolutionary viewpoint: in some way this association increases inclusive fitness (transmission of a person genotype whether by oneself or by relatives reproduction). How may this be possible? Genetic factors of cluster DO may express its features in different degrees of severity due to polygenic transmission, gene interaction and sex limited genes. Some features that compose the cluster DO (e.g. homogocigotic combinations, activations of promoting areas, etc.), interacting with environmental factors, may cause disorders, such as the APD. But most expressions of the cluster DO have an adaptative function from an evolutionary perspective. This explains that the individual genes that compose the cluster DO have not been counter-selected by evolution. Thus, we may deduce that it is this cluster DO, and not the APD itself, what has been selected by evolution; and that APD is only one of its possible outcomes.

A genetic model with similarities with ours is the "two threshold model" of Cloninger in which sociopaths are individuals on the extreme end of a normal distribution whose genetic component is polygenic and sex limited. Sex limited genes are in autosomal chromosomes, and its expression are triggered in a male (or female) chemical environment (instead of sex linked genes that are in sexual chromosomes). Sex limited genes means that females in order to be antisocial need to have a greater genetic load, thus explaining why offspring of antisocial females are at a greater risk for developing antisocial disorder. Males in sex limited model are more susceptible to environmental influences $[39,40]$.

\section{Features expressed by cluster DO}

Genetic studies, symptoms and related disorders Genetic studies, symptoms that define APD, and related disorders may provide candidates to determine the psychological functions expressed by cluster DO. Genetic studies show that the same genetic predisposition may lead to APD, drug consumption or somatization modulated by environmental influences or sex. And antisocial, narcissistic, and histrionic disorder may reflect a differential expression of the same genetic liability. These disorders tend to group around: impulsivity, aggression, and dramatic affects [20].

\section{Evolutionary view point}

From an evolutionary viewpoint some ultimate (phylogenetic) causes may be proposed to explain predispositions underlying antisocial behaviour and APD: being the dominant in social relationships, deficit in the capacity for cooperation, selfishness, aggressiveness, non-acceptance of rules, etc. We will analyse in the following the problem of hierarchy and dominance.

Hierarchy, dominance and social rules in humans. To begin with, we should realise that humans are characterized by an ambiguous attitude towards hierarchy. From one side they defy and rebel towards hierarchy and on the other side they accept and look for it [41]. However, in this equilibrium pro-social aptitudes are stronger. So, if a group has no social structure, one based up on member behaviour quickly appears. And when an established hierarchy disappear, a new one appears. This leads to a never-ending succession of temporal equilibriums. In any case this defiant behaviour has an implicit acceptance of hierarchy, as it seeks for a new hierarchy. This necessity of social structure is an expression of excessive acceptance of authority orders, hierarchy and social rules. We are inclined to be pro-social. A lot of our innate behaviour seems oriented to tolerance and acceptance of social rules [41]. We have examples from political organizations of countries and human groups. Antisocial people may explode this inclination, desiring to be dominant. This would be one of the reasons they do not accept others' rules as they experience acceptance as a domination. 
Hierarchy, dominance and social rules in non-human primates

Predisposition to dominate in social relationships is a psychological feature present in many social animals and have been extensively studied in primates. Non-human primates show social behaviours similar to ours. The closer they are, the more similar [42-48]. Common to all primate organizations is a strict hierarchy with social rules. Dyadic relationships are established between all members of community.

Gorillas' social structure is composed of a dominant male who has a harem and a territory. He has to defend both from intrusive males (42). Orangutans are solitary. Each female has a territory. A dominant male overlaps its territory to that of several females. There is an interruption in the appearance of secondary sexual characteristics in males if a dominant male is present. Violation of females by males is not uncommon, especially by those with an interruption in sexual development [42].

Chimpanzees and bonobos, are more closely related with humans. Support groups for mutual help are common and there is a fission-fusion organization with members making groups that when contact with other groups interchange members between them [42]. In the case of bonobos [43-45] females have closer relationships among themselves and dominate society structure. Males inherit their status according to that of their mothers and remain in the group. Females migrate from one community to another (in all other primate societies the sex that migrate does not dominate in society structure). War among bonobos groups is rare. Bonobos differentiate sex from reproduction, using sex for example to reduce tension when aggression may appear.

In the case of chimpanzees [46-49] fissionfusion is extreme. When food is copious communities may reach 50 individuals, if sparse, they disaggregate in small groups. In any case communities monopolize the use of a particular territory and defend it from other communities. Mature females migrate to other chimpanzee territories (female exogamy). Anthropologic studies suggest that this kind of organization is typical of early phases of human social organizations (hunter-recollecter). All males of a community are genetically related. Males dominate social structure due to their more close relationship. Aggression between chimpanzees communities are frequent and this may explain why male association is quite adaptative (male mortality due to these aggressions is higher than that of females). Preferences for other members of the community for friendship or sexual intercourse are common. Alpha male dominates all members of a community, even the alpha female. Alpha male has little tolerance to other males having intercourse with fertile females, but he cannot avoid it. An alpha male has to fight, to be supportive and to give security and comfort to maintain his status against beta males. Beta males use the same strategies to become an alpha male. Support groups of females and males decide whether to maintain the current alpha male or to choose a new candidate from the beta males. Change in alpha male is accompanied by dramatic changes in hormones in all community [49].

Discussion. Humans therefore share modules of behaviour present in chimpanzees, bonobos and in lower degree in orangutans and gorillas. However, our social structure is more flexible and more modulated by cultural experiences than that of other primates. In relation with aggressive behaviour, a higher male aggressiveness is present in almost all primates, especially from youth to mature age, declining with old age. In bonobos society this male aggressiveness may be true as well, but females dominate, due to their closer relationships and the use of alternative strategies to aggressiveness. The presence of similar modules of social behaviour and epidemiological data related with aggressiveness (higher presence in males and young) in humans to the ones found in primates, may be related with ecological conditions in our ancestors similar to the ones found in current primates.

\section{Endocrine mediators}

Related to this data in primates are endocrine and biochemical mediators. The expression of the previously described cluster DO thus is clearly sex modulated via endocrine and biochemical mediators in primates and humans. For instance, testosterone seems to increase irritability and aggressiveness, as is suggested by its level increase after the higher presence of antisocial behaviour in males $[50,51]$. This modulation from a phylogenetical viewpoint may be related with ecological conditions similar to that suffered by chimpanzees (aggressions among groups, fight for social hierarchy). This adaptative behaviour, if not modulated by education in some humans with higher genetic liability, may have pathological expressions as APD.

Temperament features: Neurochemical and neurophysiological mediators

Other features that accompany the core feature of dominance are temperament features and their 
neurochemical and physical correlates that may help in the prosecution of the adaptative function of being dominant.

We know that antisocial subjects are sensation seekers, impulsive, extrovert, have difficulty in learning from negative reinforcement, have a higher threshold to stress or anxiety stimulus [20,51-59]. This fact has its physical reflection in low skin conductance [58], low heart rate variability, decreased heart rate in anticipation to an injury or thread [58], low blinking rate to threatening stimulus [60] and other vegetative measures [61]. So APD patients face threatening stimulus and new social stimulus with more possibilities of self control than normal population. They have low harm avoidance, more attraction for the new, low reward dependence, higher threshold for anxiety, and social confrontation is not a problem for them $[36,37]$. There is a high correlation between extroversion, sociability, sensation seeking, dominance, promiscuity in sexual relationships, boredom avoidance and preference for sports [62]. All these data are in accordance with first proposed model by Eysenck and colleagues of the "General Arousal Theory of Criminality"' [63].

These temperament features and other behavioural displays of APD appear at a first look as attractive. This is the way they obtain a job (related with physical risk, competition, etc.), resources, or sexual intercourses. This attraction shows that these features have adaptative functions if under control. When the very real APD personality appears, and they are labelled as APD, they have to change their home, city or work.

\section{Game theory}

Emotions serves from an evolutionary view point both as a motivator of adaptative behaviour and as a type of communication [24]. The outward manifestation of emotions communicate probable intentions or thoughts to others. When communication of intent or one's reputation precedes interaction, this condition becomes vulnerable to deception through false signalling. Those who use deceptive strategies with a co-operator are usually referred to as "cheaters". The presence of cheaters can lead to a coevolutionary "arms race" $[64,65]$ in which potential co-operators evolve fine-tuned sensitivities to likely evidence or clues of deception, while potential cheaters evolve abilities to hide those clues.

These strategies may lead to a mixture of phenotypes and some sort of equilibrium in population. Cheating is expected to be maintained as a low-level, frequency-dependent strategy, in dynamic equilibrium with environment (e.g. social environment), which counterpressures against cheating success [24]. This dynamic process has been modelled extensively by evolutionary biologists who use the game theory which have shown that the emergence, frequency and stability of social cooperation is subject to deterrence factors [66-69].

Factors that increase cooperation are: small groups, non-random association of individuals within population, memory and recognition errors of an individual, decreasing cost of the loss in cooperator, decreasing benefits in defectors, high frequency of punishment against defectors, low cost of punishment for cooperators, etc. Society can be seen as a player in this game and APD would be a cheating strategy in equilibrium with other strategies. To reduce antisocial behaviours a society has to enforce reputation of cooperators, to establish effective mechanisms to detect cheaters and a willingness to retaliate.

We have designed a test to simulate cooperation (reciprocal altruism) situations in real life (DPOC). This test is based upon prisoners' dilemma (an application of the game theory). We have study with our DPOC test patterns of cooperation in several psychiatric populations from childhood to adulthood. Our study shows that APD compared with community controls, borderline personality disorders, psychotic stabilized patients and affective disorders are poorer in cooperation, mutual reciprocity and altruism. These patients tend to transform cooperative situations into competitive ones [70]. Furthermore, in scales that evaluate manipulation (MACH-IV) they interpret others behaviours as manipulative and score high in scales on abilities for social manipulation [71]. So APD subjectively behave as in disadvantage situation and thus rationalize their next deception. In children with attention deficit disorder and conduct disorder lack of cooperation appear as a result of novelty seeking and boredom. When those patients take metilphenidate $1 \mathrm{mg} / \mathrm{kg}$, cooperation is similar to normal population if comorbid conduct disorder is not present. However, lack of cooperation is maintained if a comorbid conduct disorder is present although metilphenidate is taken [72].

\section{Discussion}

Studies on mental disorders and normal population show that mental disorders are neither necessary nor sufficient causes of violence. Some psychiatric disorders are more easily implicated in impulsive violence, and others have extreme degrees of 
psychological features that motivate towards violence. Mentally ill are also implicated in violence without obvious causes and consequently can be unpredictable because there are undiscovered pathological symptoms, illustrating how the major determinant for violence is to have an intense motivation for an objective. Major epidemiological data related with violence in a normal population, is to be male and young and some socioeconomic factors. Among all psychiatric disorders APD have the most of the epidemiological profile associated with violent behaviour, with violence and social rule breakdown among their diagnostic criteria and genetic hereditability. Therefore, the study of APD and related disorders, is of great help in explaining violence in normal population and interactions between genes and environment.

In order to define the APD syndrome we should take into account motivations more than behaviours. For example, antisocial patients are capable of simulating cooperation, altruism, rule acceptance and control of their temper, but only if they expect some benefit or if they are under intense scrutiny of others (positive fame may help in obtaining a future greater benefit). In our opinion, APD patient's motivation is never altruist as he seeks either for concrete benefits (mainly material ones), or for being the dominant in social relationships. When a conflict in choosing between concrete benefits and social dominance appears, the second usually prevails. This may be due to the fact that, in the long run, being dominant provides more variety of benefits (material, power, etc.). Evolution appears to have favored the election of dominance over material benefits as a first option, although environmental influences may alter it. So a huge material benefit might lead APD to opt for a material benefit after a rationalization process that includes leaving its own pride intact. The determination to be the dominant in social relationships explains some unexpected behaviours in APD patients that are not easily explained by other models. All other psychological features may be understood as a phenotypical expression of these motivations, which can be found from predisposing disorders in childhood (defiant disorder) to APD in adult.

According to our evolutionary model for explaining violence in APD there is a genetic cluster that may lead to APD (cluster DO), which expresses itself in many psychological features, such as: novelty seeking, intolerance to frustration, impulsiveness, fearless, aggressiveness, higher threshold for activation of sympathetic system, competition for status, manipulation, and, as a central core for behaviour motivation, selfishness and desires of hierarchy dominance. A high expression of most of the previous features leads to some behavioural problems, such as: less tendency for social cooperation, lower altruism and higher aggressiveness. From an evolutionary viewpoint, a function of this cluster is to motivate to be the dominant in social relationships.

Cluster DO explains violence in normal population as their genetic factors are present in all the population, it also may give rise as a pathological manifestation to APD and associated risk for violence. Environmental factors (such as education or socioeconomic factors) and biological factors (such as sex and age), may modulate the expression of this cluster either increasing the risk to develop $A P D$, reducing it, or modulating its phenotypical expression giving rise to other related disorders (e.g. histrionism, narcissism, somatization, drug consumption). Sex modulation and phylogenetic function of the cluster may be due to ecological conditions in human ancestors similar to that of current primates.

Our model has some therapeutic implications. First, preventive measures are essential as once established a personality it hardly changes. Prevention includes treatment of predisposing disorders such as defiant disorder or comorbid attention deficit disorder either in children or adults (this includes psychostimulants like metilphenidate). All kind of measures to increase socialization in childhood are indispensable. Once established a violence disorder, coercion and vigilance measures (e.g. therapeutic communities) are indispensable to help that person to maintain selfcontrol. Alternative therapies, may be of utility; e.g. activities that transform psychological features such as novelty seeking or impulsiveness in more prosocial activities as adventure sports.

We hope that our evolutionary hypothesis will open new approaches in the research of the etiology of APD and the causes of violence.

\section{Acknowledgements}

This work was supported by grants of the Spanish Ministry of Science and Technology (BS2001/1224) Spanish CICYT [Interministerial Commission for Science and Technology] (RS/MS2001-16-01), and Mapfre- Fundación Alcorcon 2002 Grant.

A special tribute to the Linda Mealey, deceased in 2002, who highlighted our studies on evolutionary psychology and psychiatry.

Commentaries and review by Juan Gil Lozano MD. 


\section{References}

[1] Stuart H. Violence and mental illness: an overview. World Psychiatry 2003;2:121-5.

[2] Bourget D, el-Guebaly N, Atkinson MJ. Assessing and managing violent patients. CPA Bull 2002;34:25-7.

[3] Katz P, Kirkland FR. Violence and social structure on mental hospital wards. Psychiatry 1990;53:262-77.

[4] Shepherd M, Lavender T. Putting aggression into context: an investigation into contextual factors influencing the rate of aggressive incidents in a psychiatric hospital. J Ment Hlth 1999;8:159-70.

[5] Powell G, Caan W, Crowe M. What events precede violent incidents in psychiatric hospitals? Br J Psychiatry 1994;165: 107-12.

[6] Pescosolido BA, Monahan J, Link BG. The public's view of the competence, dangerousness, and need for legal coercion of persons with mental health problems. Am J Public Hlth 1999;89:1339-45.

[7] Marzuk P. Violence, crime, and mental illness. How strong a link? Arch Gen Psychiatry 1996;53:481-6.

[8] Hiday VA. The social context of mental illness and violence. J Hlth Soc Behav 1995;36:122-37.

[9] Wessely S. Violence and psychosis. In: Thompson C, Cowen $P$, editors. Violence. Basic and clinical science. Oxford: Butterworth/Heinemann; 1993. p. 119-34.

[10] Monahan J, Steadman HJ, Silver E. Risk assessment: the MacArthur Study of Mental Disorder and Violence. Oxford: Oxford University Press; 2001.

[11] Applebaum PS, Robbins PC, Monahan J. Violence and delusions: data from the MacArthur Violence Risk Assessment Study. Am J Psychiatry 2000;157: 566-72.

[12] Steadman HJ, Mulvy EP, Monahan J. Violence by people discharged from acute psychiatric inpatient facilities and by others in the same neighbourhoods. Arch Gen Psychiatry 1998;55:393-404.

[13] Swanson J, Swartz M, Estroff S. Psychiatric impairment, social contact, and violent behaviour: evidence from a study of outpatient committed persons with severe mental disorder. Soc Psychiatry Psychiatr Epidemiol 1998;33: S86-94.

[14] Estroff SE, Swanson JW, Lachicotte WS. Risk reconsidered: targets of violence in the social networks of people with serious psychiatric disorders. Soc Psychiatry Psychiatr Epidemiol 1998;335:95-101.

[15] Swanson JW. Mental disorder, substance abuse, and community violence: an epidemiologic approach. In: Monahan J, Steadman HJ, editors. Violence and mental disorder: developments in risk assessment. Chicago: University of Chicago Press; 1994. p. 101-36.

[16] Ramírez JM. Moral approval of aggressive acts by urban students (A cross-national study in four continents). In: Ramírez JM, Richardson DR, editors. Cross-cultural approaches to aggression and reconciliation. Huntington: NovaScience; 2001

[17] MacMillan J, Kofoed L. Sociobiology and the antisocial personality. An alternative perspective. J Nerv Ment Dis 1984;172:448-57.

[18] Cohen LE, Machalek R. A general theory of expropiative crime: an evolutionary ecological analysis. Am J Sociol 1988;93:465-501.

[19] Shweder RA, Mahapatra M, Miller JG. Culture and moral development. In: Kagan J, Lamb, editors. The emergence of morality in young children. Chigago: Chicago University Press; 1987.
[20] American Psychiatric Association. Diagnostic and Statistical Manual of Mental Disorders. American Psychiatric Association, Washington, 2000.

[21] Moffitt TE. Parental mental disorder and offspring criminal behavior: An adoption study. Psychiatry 1987;50:346-60.

[22] Robins LN, Tipp J, Prizybeck T. Antisocial personality. In: Robins LN, Regier DA, editors. Psychiatric disorders in America. New York: Free Press; 1991.

[24] Mealy L. The sociobiology of sociopathy: an integrated evolutionary model. Behav Brain Sci 1995;18:523-99.

[25] Bartol CR. Psychology and American law. New York: Wadsworth Publishers; 1984.

[26] Allen H, Lindner L, Goldman H, Dinitz S. Hostile and simple sociopaths: An empirical typology. Criminology 1997;9: 27-47.

[27] Fagan TJ, Lira FT. The primary and secondary sociopathic personality: Differences in frequency and severity of antisocial behaviours. J Abnorm Psychol 1989;3:493-6.

[28] McCord J. Personality, moral development, and criminal behavior. In: Laufer WS, Day JM, editors. Personality theory, moral development, and criminal behavior. New York: Lexington Books; 1983.

[29] Strauss CC, Lahey BB. Behavior disorders of children. In: Adams HE, Sutker PB, editors. Comprehensive handbook of psychopathology. New York: Plenum Press; 1984.

[30] Davison GC, Neale JM. Abnormal psychology. sixth ed. New York: Wiley; 1994

[31] Robins LN, Tipp J, Przybeck T. Antisocial personality. In: Robins LN, Regier DA, editors. Psychiatric disorders in America. New York: Free Press; 1991.

[32] Hare RD. Without conscience: The disturbing world of the psychopaths among us. New York: Simon \& Schuster; 1995.

[33] Mednick SA, Kirkegaard-Sorense L, Hutchings B, Knop J, Rosenberg R, Schulsinger F. An example of biosocial interaction research: The interplay of socioenvironmental and individual factors in the etiology of criminal behavior. In: Mednick SA, Christiansen KO, editors. Biosocial bases of criminal behavior. New York: Gardner Press; 1977.

[34] Hare RD. A research scale for the assessment of psychopathy in criminal populations. Pers Indiv Differ 1980;1:111-9.

[35] Harpending $\mathrm{H}$, Sobus J. Sociopathy as an adaptation. Ethol Sociobiol 1987;8:63-72.

[36] Blumstein A, Cohen J. Characterizing criminal careers. Science 1987;237:985-91.

[37] Loeber R. The stability of antisocial and delinquent child behavior: A review. Child Dev 1982;53:1431-46.

[38] Mednick SA, Gabrielli WF, Hutchings B. Genetic factors in the etiology of criminal behavior. In: Mednick SA, Moffitt TE, Stack SA, editors. The causes of crime: New biological approaches. Cambridge: Cambridge University Press; 1987.

[39] Cloninger CR, Svrakic DM, Przybeck TR. A psychobiological model of temperament. Arch Gen Psychiatry 1993;50: 975-90.

[40] Cloninger CR, Reich T, Guze SB. The multifactorial model of disease transmission: sex differences in the familial transmission of sociopathy (antisocial personality). $\mathrm{Br} J$ Psychiatry 1975;127:11-22.

[41] Eibl-Eibesfeldt I. Die Biologie des menschlichen Verhaltens. Grundlagen der Humanethologie. München: Piper; 2004.

[42] Maggioconcalda AN, Czekala NM, Sapolsky R. Male orangutan subadulthood: a new twist on the relationships between chronic stress and developmental arrest. Am J Phys Anthropol 2002;118:25-32.

[43] Wrangham R, MC Grew WC, de Waal FBM, Heltne P. Chimpanzee cultures. Cambridge: Harvard University Press; 1994. 
[44] Randall LS. The pygmy Chimpanzee: evolutionary biology and behavior. New York: Plenum Press; 1984.

[45] Kano T. The last ape: pygmy chimpanzee behavior and ecology. Cambridge: Harvard University Press; 1992.

[46] De Waal FBM. Peacemaking among primates. Cambridge (UK): Harvard University Press; 1989.

[47] Ghiglieri MP. The chimpanzes of Kibale Forest. Columbia (USA): Columbia University Press; 1984.

[48] Goodall J. Population dynamics during a 15 year period in one community of free-living chimpanzees in the Gombe National Park, Tanzania. J Comp Ethol 1993;61: $1-60$.

[49] de Waal FBM. Chimpanzee politics. Power and sex among apes. Baltimore (MA): Johns Hopkins University Press; 1988.

[50] Ramírez JM. Human aggression: a multifaceted phenomenon. Madrid: Centreur; 2003.

[51] Ramírez JM. Hormones and aggression in childhood and adolescence. Aggress Violent Behav 2003;8(6):621-44.

[52] Hare R. Hare Psychopathy Checklist Revised (PCL-R). Toronto: Multihealth Systems; 1991.

[53] Cooke D. Psychopathy: Theory, research and implications. Dordrecht: Kluwer; 1998.

[54] Lykken DT. Psychopatic personality. In: Encyclopedia of psychology. New York: Wiley; 1984. p. 165-7.

[55] Meloy RR. The psychopathic mind. Nortvale (NJ): Aronson; 1988.

[56] McCord W. The psychopath and milieu therapy. New York: Academic Press; 1982

[57] Torgensen S. Genetics in Borderline conditions. Acta Psychiatr Scand 1994;379:19-26.

[58] Lykken DT. The antisocial personalities. Nillsdale (NJ): Erlbaum; 1995.

[59] Hare R, Schalling D. Psychopathic behavior: approaches to research. Chichester: Wiley; 1978.
[60] Patrick CJ. Emotion and psychopathy: starling new insights. Psychophysiology 1994;31:319-30.

[61] Patrick CJ, Cuthbert BN, Lang PJ. Emotion in the criminal psychopath: fear image processing. J Abnorm Psychol 1994;103:523-4.

[62] Daitzman RJ, Zuckerman M. Personality, disinhibitory sensation seeking and gonadal hormones. Pers Indiv Differ 1980;1:103-10.

[63] Eynseck HJ, Gudjonsson C. The causes and cures of criminality. New York: Plenum; 1989.

[64] Trivers RL. The evolution of reciprocal altruism. Quart Rev Biol 1971;46:3-37.

[65] Quiatt D. Which are more easily deceived, friends or strangers? Behav Brain Sci 1988;11:260-1.

[66] Axelrod R, Hamilton WD. The evolution of cooperation. Science 1981;211:1290-396.

[67] Axelrod R, Dion D. More on the evolution of cooperation. Science 1988;242:1385-90.

[68] Boyd R. Is the repeated prisioner's dilemma game a good theoretical model of reciprocal altruism? Ethol Sociobiol 1988;9:211-21.

[69] Hirschleifer J, Cooll JC. What strategies can support the evolutionary emergence of cooperation? J Conflict Resolut 1988;32:36-398.

[70] Montañés Rada F, De Lucas Taracena MT. Evaluación del Trastorno Antisocial con el dilema del prisionero. Act Esp Psiquiatr 2003;31:307-14.

[71] Montañés Rada F, de Lucas Taracena MT, Martín Rodríguez MA. Valoración de la inteligencia maquiavélica en el trastorno antisocial mediante la Escala MACH-IV. Act Esp Psiquiatr 2004;32:65-70.

[72] Montañés Rada F, de Lucas Taracena MT, Estrada E, Catalán $P$. Cooperation in attention deficit disorder evaluated with DPOC. In: Poster presentado en el VI International congress of Personality, Zaragoza, Spain, 2004. 